\begin{tabular}{|l|l|}
\hline América Latina y el "discurso colonial": perspectivas críticas & Titulo \\
\hline Gómez Arredondo, David - Autor/a; & Autor(es) \\
\hline $\begin{array}{l}\text { De Raíz Diversa. Revista Especializada en Estudios Latinoamericanos (Vol. 2 no. 4 } \\
\text { jul-dic 2015) }\end{array}$ & En: \\
\hline México D.F. & Lugar \\
\hline $\begin{array}{l}\text { Programa de Posgrado en Estudios Latinoamericanos, Universidad Nacional } \\
\text { Autónoma de México }\end{array}$ & Editorial/Editor \\
\hline 2015 & Fecha \\
\hline $\begin{array}{l}\text { Mignolo, Walter; Jáuregui, Carlos; Seed, Patricia; Colonialidad; Decolonialidad; } \\
\text { Modernidad; Postcolonialismo; Semiótica; Discurso colonial; Ortega, Julio; América } \\
\text { Latina; }\end{array}$ & Colección \\
\hline Artículo & Temas \\
\hline $\begin{array}{l}\text { "http://biblioteca.lacsoedu.ar/Mexico/ppel-unam/20160627032334/David_Gomez__America_Latina__el_discurso_colonial-perspectivas } \\
\text { criticas.pdt" }\end{array}$ & URL \\
\hline $\begin{array}{l}\text { Reconocimiento-No Comercial-Sin Derivadas CC BY-NC-ND } \\
\text { http://creativecommons.org/licenses/by-nc-nd/2.0/deed.es }\end{array}$ & Licencia \\
\hline
\end{tabular}

Segui buscando en la Red de Bibliotecas Virtuales de CLACSO http://biblioteca.clacso.edu.ar

Consejo Latinoamericano de Ciencias Sociales (CLACSO)

Conselho Latino-americano de Ciências Sociais (CLACSO)

Latin American Council of Social Sciences (CLACSO)

www.clacso.edu.ar

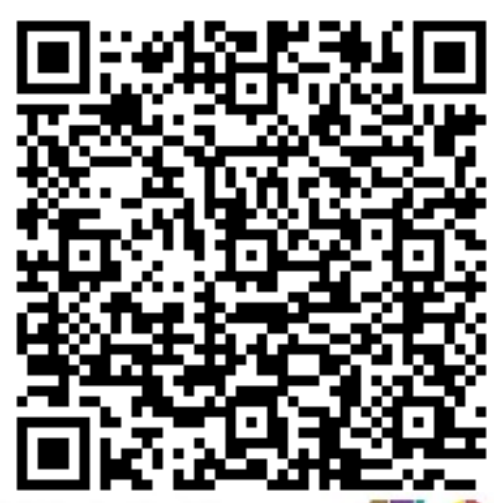

Consejo Latinoamericano de Ciencias Sociales

Conselho Latino-americano de Ciências Sociais 


\section{América Latina y el "discurso colonial”: perspectivas críticas}

David Gómez Arredondo

RESUMEN. El artículo considera de manera crítica un eje problemático de los enfoques "poscoloniales" y "decoloniales", relativo al discurso, la semiosis y la representación textual. Para avanzar en esa tarea, se detiene en varios momentos y facetas del debate, examinando algunas posiciones de Patricia Seed, Carlos Jáuregui, Walter Mignolo y Julio Ortega. Se busca explorar este terreno para plantear un abordaje complejo de las prácticas discursivas coloniales, sin desechar enfoques y perspectivas ajenas al bloque teórico de la "modernidad/ colonialidad".

Palabras Clave: Discurso colonial, semiosis colonial, teoría poscolonial, América Latina.

Aвstract. The article critically evaluates the problematic axis of the "postcolonial" and "de-colonial" approaches which are relative when speaking about the discourse, semiosis and textual representation. In order to proceed in this task, the author looks into various moments and facets of the debate between the two approaches examining certain ideas presented in the works of Patricia Seed, Carlos Jáuregui, Walter Mignolo and Julio Ortega. The author seeks to explore their claims to be able to analyze in a complex manner the colonial discursive practices without forgetting or laying aside theoretical approaches and perspectives different from the "modernity/coloniality" block.

KEYWORDs: Colonial discourse, colonial semiosis, postcolonial theory, Latin America.

Recibido: 30 de abril de 2015. Aceptado: 29 de mayo de 2015.

\section{INTRODUCCIÓN}

\section{$\mathrm{E}$} última instancia remiten a ciertos desarrollos de posiciones que en sus inicios no se distinguían de las propuestas "poscoloniales", se puede separar un núcleo problemático que remite al "discurso". Temas relativos al discurso y la semiosis colonial, la representación textual y el habla del sujeto colonizado se extendieron en varios estudios, aunque con menor carácter 
sistemático y perdiendo en muchos casos la agudeza metodológica que habían mostrado sus predecesores. Por ejemplo, la forma en que Edward Said utilizó la noción de "formación discursiva" procedente de la arqueología de Foucault representa un antecedente claramente más incisivo y no superado en vertientes posteriores. (Said, 2002; Vega, 2003: 65-152) El análisis del "orientalismo" como formación discursiva le permitía a Said atravesar transversalmente un "archivo", hacer un recorte y analizar novelas, libros de viajes o tratados filológicos, abordándolos conjuntamente. Uno de los objetivos de Said consistía justamente en mostrar que varios géneros y tipos diferentes de enunciados constituyen una misma formación discursiva, el orientalismo, formación que está entremezclada con el poder imperial occidental. Said referirá la pretensión continua del discurso estético y erudito "orientalista" de fijar a su objeto y construir un conjunto de tópicos y estereotipos sobre el "Otro", que terminarán siendo una camisa de fuerza discursiva y conceptual.

Después de ese tipo de intervenciones teóricas, la cuestión del "discurso colonial" se consideró pertinente para analizar algunos procesos latinoamericanos. Para ello, se abordó un cuerpo textual situado en otro momento histórico, cuyo inicio podríamos situar a fines del siglo xv. En lo que sigue, consideramos, de manera crítica, algunos momentos de estos desarrollos analíticos.

\section{LA PROBLEMÁTICA DEL 'DISCURSO COLONIAL' EN LOS INICIOS DEL DEBATE POSCOLONIAL LATINOAMERICANO. HACIA UNA RECONSTRUCCIÓN}

Una de las vías abiertas para la reconstrucción histórica del pensamiento poscolonial latinoamericano podría tomar como referente algunos aspectos de un debate que se publicó en la revista Latin American Research Review a principios de la década de 1990. En este debate, la historiadora Patricia Seed y los críticos literarios Hernán Vidal, Walter Mignolo y Rolena Adorno delinearon las implicaciones y el impacto que para el estudio de América Latina tenían las perspectivas abiertas por las obras de Edward Said, Gayatri Spivak, Homi Bhabha y Ranajit Guha, principalmente. El punto de partida se encuentra en la reseña-artículo de Patricia Seed, "Colonial and Postcolonial Discourse", en donde la autora indicaba una tendencia reciente en el marco de la historia y la antropología, en la que se asumía cada vez con más fuerza que la práctica historiográfica y etnográfica está permeada de dispositivos retóricos y literarios. (Seed, 1991) De hecho, como iremos viendo, aunque Seed hace comparecer a la antropología, la literatura y la historia 
para discutir la noción de "discurso colonial", en el trasfondo de su lectura se encuentra una concepción filosófica del lenguaje, derivada de la recepción norteamericana del así llamado post-estructuralismo francés. Hay en este artículo una interpretación del cruce de disciplinas en diferentes obras sobre el colonialismo y sus secuelas, en un contexto teórico que la propia Seed califica como un "momento profundamente interdisciplinario" (1991: 181182) Para ir situando algunos contenidos del debate y del tipo de enfoque asumido en este artículo por Seed, conviene colocar inicialmente dos niveles paralelos de discusión. Uno de ellos remite al descrédito que según la autora habría afectado a los recuentos históricos y antropológicos del colonialismo, que seguían dos líneas de reconstrucción. En un primer tipo de enfoque se enfatiza la heroica resistencia de los nativos, quienes habrían defendido dramáticamente su territorio. En el segundo acercamiento, los nativos se acomodaron al orden colonial, modificando los objetivos de este orden para que sirvieran a sus propios fines. Según Seed, para finales de la década de 1980 ambos tipos de acercamiento al colonialismo se mostraban cada vez más como "mecánicos, homogeneizantes e inadecuados como versiones del encuentro entre colonizados y colonizadores." (1991: 182) En forma paralela al descrédito de ambos tipos de recuentos del colonialismo, Seed ubica un emergente "movimiento intelectual" entre varios pensadores, que son agrupados como "post-estructuralistas". La enumeración que hace Seed de este grupo incluye figuras tan diversas como Jean-Francois Lyotard, Roland Barthes, Jacques Derrida, Gilles Deleuze, Félix Guattari, Michel Foucault y Richard Rorty (Seed, 1991: 182). Ya a estas alturas del artículo se podría argumentar la arbitrariedad de esta clasificación, aunque no intentaré cuestionar la fidelidad de Seed a los textos de todos estos autores, tarea que nos llevaría a otro terreno. Más bien, quisiera señalar lo que encuentra la autora en este "movimiento", ya que se convertirá en el punto de partida para acceder al ámbito del "discurso colonial":

Un tema obligado examinado por estos diversos autores consiste en la crítica de la transparencia de los lenguajes como vehículos de comunicación. Palabras, oraciones y frases pueden tener más de un significado y más de una interpretación simultáneamente. Cómo sean las palabras y las frases interpretadas y entendidas depende de la determinación del contexto, aunque a su vez la comprensión del contexto depende de la interpretación o traducción de las palabras y frases en cuestión. Dentro de este marco, el reconocimiento de lo que los teóricos llaman el carácter polisémico del lenguaje (la posibilidad de una palabra de tener múltiples e incluso contradictorios significados) ha abierto la puerta a un amplio espectro de posibi- 
lidades interpretativas en historia, literatura y antropología. En este ámbito, el conocimiento de las prácticas culturales de una sociedad ha llegado a jugar un papel central para establecer posibilidades interpretativas más amplias para palabras, oraciones y frases en un tiempo o cultura dadas.

El concepto de discurso colonial, por lo tanto, ha redirigido la reflexión crítica contemporánea sobre el colonialismo (y sus consecuencias) hacia el lenguaje usado por conquistadores, administradores imperiales, viajeros y misioneros. Ya que fue a través del lenguaje-las figuras retóricas del habla y las formaciones discursivas- como los europeos han entendido y gobernado tanto a sí mismos como a los pueblos que sujetaron en ultramar. Al reflexionar sobre el marco lingüístico en el que la política del dominio colonial se elaboró, algunos autores se han percatado de las limitaciones de los discursos políticos europeos, así como del modo en el que el carácter polisémico del lenguaje ha permitido a los nativos de territorios colonizados apropiarse y transformar los discursos de los colonizadores. (Seed, 1991: 182-183)

Dos importantes consecuencias deriva Seed del impacto del pensamiento post-estructuralista en el campo de los estudios del colonialismo. En una de ellas se cuestiona al sujeto soberano como autor, a partir de algunas indicaciones de Roland Barthes y Michel Foucault, pero principalmente Seed intenta mostrar la trama común que compartiría el humanismo europeo occidental con el imperialismo. En forma paralela, y construyendo un análisis basado en las tesis sobre el lenguaje ya mencionadas, Seed encuentra en el post-estructuralismo el intento de desalojar la "intención" del autor o el "significado original" del lugar central, permitiendo que los críticos literarios y otros consideren las formas en las que el texto es apropiado y usado por varias comunidades textuales.

Para mostrar la vigencia de estas concepciones y sus consecuencias para el estudio del colonialismo en América Latina, Seed reseña cinco obras publicadas a fines de la década de 1980. Lo que cabe enfatizar acerca de las conclusiones que extrae Seed de esta revisión es la dimensión crítica que encuentra en este tipo de conocimiento. Según esta autora, el objeto de la crítica de estos nuevos enfoques son las relaciones de autoridad en los Estados coloniales y postcoloniales. Y la crítica se distinguiría o dividiría en diferentes modalidades: crítica de relaciones económicas de autoridad, de relaciones culturales de autoridad (como el canon literario) y crítica de relaciones políticas de autoridad.

Antes de continuar con el debate iniciado por Seed, detengámonos un poco en las consecuencias de este momento clave para el debate poscolonial latinoamericano. Esta aproximación al "discurso colonial", construida 
a partir del encuentro entre nuevos enfoques teóricos acerca del lenguaje y la representación, con un descrédito de formas previas de explicar los procesos coloniales marcará una línea o una veta que se recorrerá posteriormente. Lo que habría que plantear en relación a este tipo de propuestas es el complejo terreno al que ingresan al insistir en que los discursos, la significatividad le es constitutiva e inmanente a las prácticas sociales e históricas, de tal modo que no podríamos distinguir entre un "discurso colonial" y las prácticas de poder y dominación que lleva consigo. Sin pretender resolver por ahora este denso problema teórico, relativo a la relación entre prácticas discursivas y no discursivas, sólo cabría señalar que ya en el artículo de Seed de 1991 tendríamos una toma de posición al respecto. Podríamos sostener la hipótesis de que en este comienzo del debate poscolonial latinoamericano ya está en ciernes el procedimiento de inflar y darle un fuerte relieve a las prácticas de representación y a las formaciones discursivas en la revisión del colonialismo en América Latina. Como un camino a recorrer, esbozado apenas en el artículo de Seed, se encontraría latente la puesta de lado o el franco desconocimiento de mecanismos de dominación materiales inscritos en el orden colonial, como la apropiación de plus-trabajo de comunidades indígenas o afrocaribeñas, que le dieron un sello a ese orden durante siglos.

En el artículo de Hernán Vidal "The Concept of Colonial and Postcolonial Discourse: A Perspective from Literary Criticism” se sitúa la propuesta de Seed en el marco de la historia de la crítica literaria latinoamericana de las décadas previas. Sobre este texto, es preciso señalar la toma de posición frente a la vertiente poscolonial y el momento intelectual que se refleja allí. Vidal alertaba sobre un posible resultado de la promoción de este tipo de debate: la institucionalización de lo que Seed consideraba como un nuevo "movimiento intelectual". (Vidal, 1993: 114) Claramente fue eso lo que ocurrió, y a Vidal le preocupaba que la insistencia en la novedad de los enfoques teóricos puestos en juego en este marco eclipsara la relación con la tradición del pensamiento crítico latinoamericano:

Dejando de lado la cuestionable separación de las dimensiones sociales, culturales y políticas mi primera objeción es que en el esfuerzo por llamar la atención a la nueva etiqueta del "discurso colonial y poscolonial", que se originó en los estudios culturales de la India posteriores a la independencia que siguió a la Segunda Guerra Mundial, no se pueden olvidar categorías que se han establecido firmemente por más de veinte años en la historiografía y en la crítica literaria relativas a condiciones sociales específicas. 
Me refiero aquí a los conceptos de dependencia y de análisis ideológico. (Vidal, 1993: 118)

Aquí tendríamos un anuncio de una crítica al pensamiento poscolonial latinoamericano que se consolidaría más tarde. La desconfianza de Vidal hacia cierta tendencia que ya era perceptible en los inicios del "giro poscolonial" latinoamericano, consistente en dejar de lado la tradición intelectual y de pensamiento crítico de la región, para introducir repentinamente un nuevo bagaje teórico, fuertemente marcado por el post-estructuralismo e inclusive por cierta "posmodernidad" sería continuada con posterioridad. (Roig, 2001: 133-154; Achúgar, 1998)

\section{CANibalia de Carlos Jáuregui. Para una CRítica de su mÉTOdo}

Canibalia, el amplio y ambicioso estudio de Carlos Jáuregui, actualmente profesor de literatura latinoamericana y antropología en la Universidad de Notre Dame, en Estados Unidos, constituye una muy peculiar intervención epistemológica y académica. A lo largo de su extenso estudio se puede uno percatar de la amplitud de miras del autor, no sólo en el manejo de varias fuentes, las cuales son analizadas a través del tamiz de ciertos debates teóricos actuales, sino en el uso, por ejemplo, de mapas, cartografías e iconografías como fuentes para el análisis del tropo, de la metáfora del canibalismo y del consumo.

Cabe agregar que, en el marco de las propuestas "decoloniales" tan difundidas recientemente, Canibalia ocupará quizá en el futuro un lugar muy particular, por varias razones. En primer lugar, se trata de un intento unificado por interpretar varios momentos de la historia intelectual y cultural de nuestra América, pretendiendo darle un giro a los enfoques y aproximaciones precedentes. Su análisis de fuentes está entremezclado con un recurso continuo a ciertos tópicos del debate "poscolonial" e inclusive se perciben bastantes resabios y persistencias de la "posmodernidad", que en este contexto sólo pretende nombrar la manera en que se receptaron temáticas procedentes del "post-estructuralismo francés" en la academia norteamericana. Justamente, será éste eje el que me guiará para realizar algunas consideraciones sobre los alcances de su método, no solamente tal y como es anunciado, sino como es puesto en práctica. En lo que sigue me atendré a los dos primeros capítulos, de seis de los que consta el volumen, para comenzar un examen de la puesta en movimiento del método y el enfoque anunciados en la introducción. 
El propio Jáuregui sitúa su estudio en el marco de la "crítica tropológica" (2008: 16), que en este caso toma como punto de arranque y como destino final a la figura del canibalismo, no como una práctica existente o susceptible de ser comprobada, sino a partir de su inscripción en el discurso colonial. Su apropiación del tópico del supuesto carácter irrebasable de la metáfora, lo lleva a borrar cualquier límite estable entre el discurso literal y el discurso metafórico, de tal modo que todo acto de habla y toda enunciación están habitados por la inestabilidad y los tránsitos abruptos de las metáforas. Buena parte de Canibalia se puede situar en una vertiente de la producción teórica poscolonial, cuyo interés fundamental consiste en examinar al colonialismo a partir de sus inscripciones textuales y su producción discursiva. Esta forma de proceder, anunciada en la introducción, nos permitirá analizar sus alcances y limitaciones.

Jáuregui documenta la emergencia y la recurrencia de la figura del "caníbal-caribe" en las inscripciones discursivas de Colón, comenzando con su primera aparición a fines de noviembre de 1492. En esta sección, introduce un concepto, el de "archivo", con el cual intentará explicar el uso de ciertos motivos culturales europeos que sirvieron para confrontarse con las realidades americanas:

La asimilación descansa tanto en el archivo previo (que es de donde vienen estos monstruos mencionados por Colón), como en las observaciones de las realidades americanas (que es donde no se encuentran los monstruos). En esa tensión aparece la salvedad de Colón; y en ella, hacen su equívoca entrada los caníbales. (Jáuregui, 2008: 51)

Se trataría, en primer lugar, de una especie de depósito cultural, de un imaginario europeo de lo monstruoso, al que recurriría Colón para nombrar las realidades que se encuentran ante él en el Caribe. En esta sección, ya podemos ver un procedimiento que pone en juego constantemente Canibalia: el análisis de las prácticas discursivas europeas en busca de algunos motivos culturales que funcionarán como mediaciones frente al mundo colonizado. Al abordar el tema del archivo europeo que clasifica y cataloga a lo "alterativo", Jáuregui encuentra antecedentes greco-latinos, transmitidos a lo largo de siglos, en los que se nombró y describió a escitas, andrófagos o amazonas. Pero a la vez Canibalia busca ampliar el ámbito observado, y analiza los grabados de Johanes Froschauer de 1505 o de Theodore De Bry de 1525 a 1528; esto nos lleva a concluir que el "archivo" no es exclusivamente textual y discursivo, sino que abarca también 
las imágenes y representaciones cartográficas. Y, paralelamente, Jáuregui va construyendo un andamiaje conceptual, de origen psicoanalítico, que busca dar cuenta del deseo y el horror frente al "Otro". Allí, recurrentemente se basará en los usos de Homi Bhabha del psicoanálisis para intentar interpretar la construcción discursiva del sujeto colonizado. En cierto modo, podríamos afirmar que Jáuregui busca explorar las construcciones culturales europeas del mundo colonial americano, situando al "canibalismo" en ese marco.

¿Qué implicaciones tiene el uso no sólo de la categoría de "archivo", sino el enfoque discursivo, textual e iconográfico en torno a los comienzos de la expansión colonial europea? Canibalia se interroga en esta primera parte que comentamos por la construcción textual del "Otro" colonizado. Sin duda, la dimensión discursiva debe formar parte de cualquier recuento de los procesos históricos a los que se refiere la primera parte de Canibalia. Sin embargo, debido a su explícita aceptación de un enfoque fragmentario, Jáuregui no intenta partir del universo discursivo de la época y así situar al colonialismo ibérico en el marco de la conflictividad social, constatable en varios niveles. De esta forma, el tropo, la figura del caníbal, perseguida en Canibalia por medio de una selección de fuentes pierde consistencia en algunas ocasiones.

Aún así, en esta primera parte Jáuregui no deja de captar la forma en que, en la construcción inicial de una imagen del "caribe", su ubicación territorial y la cartografía colonial que pretende fijarlo espacialmente se vuelven cada vez más arbitrarias. "Caribes" serán las colectividades que resisten a la dominación y sujeción colonial; el significado de esa expresión se irá desligando de la práctica antropofágica en los documentos jurídicos de la época. Consideremos la designación de la Corona del 15 de noviembre de 1505:

Por vuestra carta escreuis que alla es menester saber quales indios son los que se pueden cabtivar para que se puedan traer a esta isla por esclauos para se servir dellos. Los que se pueden cabtivar sy no quisyeren obedescer son los que se disen canyvales que son los de las yslas de san bernaldo e isla fuerte e en los puertos de cartajena... (Jáuregui, 2008: 79)

De hecho, la exigencia de los encomenderos de ampliar progresivamente los alcances territoriales del trabajo forzado indígena irá definiendo el discurso sobre el canibalismo a lo largo del siglo xvi. Recordemos que entonces ocurre la destrucción de las comunidades indo-caribeñas, 
las cuales son esclavizadas masivamente. En este marco, Jáuregui documenta la recurrencia del discurso sobre el "otro" indocaribeño, acusado de canibalismo y, con ello, una y otra vez se pretendía justificar su captura y venta como esclavo. Es particularmente en este apartado intitulado "Canibalismo y geografía encomendera" donde podríamos plantear algunas tensiones en la aproximación de Jáuregui. Por un lado, Canibalia no encuentra asidero en un terreno no-textual o no-discursivo. En buena medida, en consonancia con algunos enfoques teóricos recientes, Jáuregui suscribe la idea de que la realidad social es coextensiva con las construcciones discursivas. En una aproximación de este tipo, dar cuenta de las formaciones discursivas supone a la par explicar la realidad social de la que aquellas emergen. Por ello, al poner en primer plano la formación discursiva colonial que se edifica en torno al "canibalismo", Jáuregui pretende, al mismo tiempo, mostrar la manera en que al construir la figura del otro monstruoso, abyecto y caníbal, se creaban las condiciones para su cautiverio y esclavitud:

La imputación de canibalismo a los aborígenes debe ser leída bajo el entendido de que hizo parte de la construcción de un Otro sujeto de dominación y que, funcionalmente, fue una coartada jurídica para la expansión imperial, la sujeción de los pueblos indígenas y su virtual aniquilación. (Jáuregui, 2008: 87)

A través de esta argumentación, se podría cuestionar que de hecho siga Jáuregui, como lo afirma en la introducción, un método fragmentario, cuyos objetos de discurso no son más que índices del colonialismo, con innumerables mediaciones, traducciones, silencios y olvidos (2008: 23) Traicionando esas aseveraciones programáticas, en el apartado sobre canibalismo y geografía encomendera hay un intento por remitir el fragmento textual y discursivo a la totalidad histórica y social en la que se inscribe. De esta forma, la representación discursiva del "otro" como caníbal formó parte de un proceso histórico de expoliación y sujeción a gran escala, llevado a cabo hasta sus últimas consecuencias en la primera mitad del siglo xvi. El trabajo forzado indígena estuvo entremezclado con una formación discursiva que describía a los indios como "bárbaros" por sus prácticas, y que les negaba de esa forma la condición de sujetos de derecho. En buena medida, esta dimensión del comienzo del colonialismo ibérico en América, la sujeción y explotación de grandes masas de indígenas, si bien se imbrica con la construcción discursiva del "otro", también 
se debe analizar con un marco categorial específico, que busque explicar la apropiación del trabajo y de sus productos en sus propios términos. Allí, la materialidad de las relaciones sociales tiene cabida, si bien no se puede separar por completo de las formaciones discursivas y de la multiplicidad de enunciaciones que atraviesan al cuerpo social, manifestando y ocultando la conflictividad social. Quizá por ello, para analizar el colonialismo en nuestra América, es necesario ampliar el horizonte y no circunscribirse solamente al archivo cultural y al imaginario europeo, aunque al hacerlo se pretenda desmontar sus figuras retóricas, señalando las prácticas de dominación que conllevan, como intenta Jáuregui en la primera parte de Canibalia. En las mismas fuentes del siglo XvI, y particularmente entre los misioneros de diversas órdenes que intentaron darle voz a las comunidades invadidas, hay alusiones a la discursividad india en ese trágico contexto colonial. Canibalia se detiene en la figura de Bartolomé de las Casas y analiza con detalle la inversión del tropo del caníbal en varias de sus obras, de tal modo que para el dominico fueron los españoles semejantes a lobos hambrientos que consumían a los indios. Sin embargo, la forma en que se traslucen las voces indígenas en el cuerpo textual lascasiano no es abordado sistemáticamente.

LENGUAJE Y CONTROL COLONIAL EN EL LADO MÁS OSCURO DEL RENACIMIENTO

El lado más oscuro del Renacimiento, libro de Walter Mignolo, crítico literario y semiólogo argentino asentado en los Estados Unidos, ha sido incluido reiteradamente en el marco de la producción "poscolonial" sobre América Latina. (Mignolo, 1995) Se trata de un estudio que se centra fundamentalmente en los siglos XVI y XVII, pretendiendo abordar de modo diferente los inicios del colonialismo en América, a partir de una propuesta metodológica a la que caracteriza como "hermenéutica pluritópica". En lo que sigue abordaré la forma en que procede Mignolo en la primera sección de su libro dedicada a la "colonización del lenguaje", con lo que buscaré aclarar qué significa la "hermenéutica pluritópica", así como las limitaciones asociadas a su enfoque. Pero previamente iré situando la problemática del "discurso colonial", así como de la "semiosis colonial".

En la introducción de El lado más oscuro del Renacimiento, Mignolo ubica un campo problemático, un ámbito de estudios que había surgido recientemente, cuyo estatuto y nombre se encontraban en debate. La cate- 
goría de "discurso colonial" había sido definida por Peter Hulme, abarcando todo tipo de producción discursiva vinculada con y elaborada en situaciones coloniales. En este enfoque, la categoría de "discurso colonial" sitúa a la producción discursiva en un contexto de interacciones conflictivas, de apropiaciones y resistencias, de poder y dominación. (Mignolo, 1995: 7) Más adelante volveremos sobre la importante cuestión del poder, tal y como se expresa en el terreno del discurso, ya que aunque es mencionado en la introducción, se irá desdibujando en la sección sobre el lenguaje de El lado más oscuro del Renacimiento.

Mignolo aprobará algunos aspectos de la categoría de "discurso colonial", ya que incluye interacciones tanto orales como escritas, pero a su vez cuestionará los alcances del concepto, debido a que éste no puede dar cuenta de "interacciones semióticas entre diferentes sistemas de escritura", como el alfabeto latino introducido por los españoles, el sistema de escritura picto-ideográfica de Mesoamérica y los quipus del Perú colonial. (1995: 7-8).

La sección sobre la colonización del lenguaje de El lado más oscuro del Renacimiento se moverá alrededor de dos ejes, detallados en sendos capítulos. Inicialmente, la atención girará alrededor de la problemática de la letra y de la escritura en la filosofía renacentista del lenguaje subyacente en la obra de Antonio de Nebrija y de José de Aldrete. Nebrija escribió a fines del siglo xv tanto una gramática del latín como una del castellano. Uno de los principios de sus gramáticas, enfatizado en las introducciones, consistía en pronunciar como se escribe, esto es, en domar la voz a partir del texto escrito. En la interpretación de Mignolo, hubo una consecuencia indirecta de la difusión de la gramática latina de Nebrija, claramente perceptible en la forma en que los misioneros de distintas órdenes religiosas se confrontaron con las lenguas amerindias. Al concebir a la escritura como representación de la voz, los misioneros obstruyeron su comprensión del funcionamiento de los sistemas gráficos nahuas y mayas y se vieron incapacitados para captarlos como formas de transmisión de conocimiento. Por otra parte, los misioneros se abocaron a difundir la letra y la escritura occidentales en el nuevo contexto colonial, y para ello redactaron innumerables gramáticas de las lenguas amerindias. Según Mignolo, en el curso de la realización de esta tarea la tradición clásica sufrió una inversión, la letra dejó de tener el lugar subordinado que le atribuyó Aristóteles y los sistemas no alfabéticos de escritura fueron suprimidos. 
Conviene detenerse en este punto para examinar esta última aseveración de El lado más oscuro del Renacimiento: ¿estrictamente fueron suprimidos los sistemas no alfabéticos de escritura por el poder colonial? Pareciera que es necesario matizar bastante la interpretación de Mignolo para captar algunas dimensiones del poder colonial en los siglos XVI y XViI. En primer lugar, aceptando la destrucción masiva de documentos pictográficos ocurrida durante las primeras décadas de la instauración del orden colonial. El propio Mignolo refiere un pasaje de Diego de Landa, misionero franciscano asentado en Yucatán:

Esta gente usaba ciertas letras o caracteres, con los cuales escribía en sus libros sobre sus antigüedades y ciencias; con éstas, y con figuras y ciertos signos en sus figuras entendían sus asuntos, los hacían conocer y los enseñaban. Encontramos un gran número de libros con estas letras, y como no contenían nada sino supersticiones y falsedades del demonio los quemamos todos, lo cual ellos lo tomaron con gran aflicción y les dio gran dolor. (Mignolo, 1995: 71)

Esta destrucción masiva y sistemática de los soportes gráficos del conocimiento amerindio ocurrió en gran escala en toda la Nueva España durante sus primeras décadas de existencia, de tal forma que posteriormente cronistas como Juan Bautista Pomar, Motolinía, Fray Diego Durán o Torquemada se quejaron de ese proceder inicial, al encontrarse escasos de fuentes. Sin embargo, no es la única dimensión del poder colonial que es preciso comprender, ya que durante buena parte del siglo xvi también ocurrió que documentos pictográficos coexistieron con la escritura alfabética e inclusive fueron mandados a elaborar por instrucciones del cuerpo administrativo del virreinato. ¿Cómo explicar de otro modo la existencia del Lienzo de Tlaxcala, muy probablemente pintado a solicitud del virrey Luis de Velasco entre 1550 y 1564? (Gruzinski, 2007: 30) Y recordemos que éste mantiene en buena medida la factura tradicional y representó los nombres de lugares, de fechas y de protagonistas con sus respectivos glifos. Más bien pareciera que el poder colonial durante el siglo xvi alcanzó a establecer una relación estratégica con las formas amerindias de producción y transmisión de saber. Inclusive la recopilación de la "palabra antigua", de los huehuetlahtolli desde las labores de fray Andrés de Olmos, hasta la actividad del franciscano Bernardino de Sahagún se podría entender como un modo estratégico de vincularse con el saber de los vencidos. En esa ola intensiva de evangelización, que Serge Gruzinski sitúa alrededor 
de 1540 , los misioneros comenzaron a separar de modo tajante los saberes amerindios a los que se podía recurrir sin que supusieran una amenaza para el poder eclesial y el orden colonial que se estaba cimentando.

Ahora, volviendo a otro de los planteamientos de Mignolo de El lado más oscuro del Renacimiento, en el que se especifica la cuestión del vaciamiento de las lenguas amerindias en el molde gramático del latín, podremos vislumbrar otra serie de problemáticas. En el Arte de la lengua castellana y mexicana (1571) de Alonso de Molina o en El Arte de la lengua mexicana (1645) del jesuita Horacio Carochi, Mignolo encuentra un procedimiento constantemente reiterado: se buscaba hacer corresponder los sonidos de la lengua amerindia con las letras del alfabeto latino, indicando si había diferencias que la lengua indígena en cuestión carecía de determinadas letras. Y también se ajustaba la gramática, por ejemplo del náhuatl en el Arte de Molina, quien dividía en ocho partes las oraciones de esa lengua, del mismo modo que Nebrija procedió en su gramática latina. A esta práctica de ajustar y "reducir" las lenguas amerindias al molde latino la coloca Mignolo en el plano de la "colonización del lenguaje." Este vaciamiento necesariamente tenía que ir acompañado por la descalificación y devaluación de los sistemas pictográficos, según el argumento de $E l$ lado más oscuro del Renacimiento. Pues bien, si pensamos que el alfabeto latino no sólo iba en una dirección, sino que también podía, hasta cierto punto, ser apropiado por los sujetos indios y utilizado estratégicamente, tendremos un cuadro más complejo. Consideremos el primer texto en náhuatl escrito en el alfabeto latino en una fecha tan temprana como 1528. Se trata del escrito que fuera incluido en los Anales históricos de la nación mexicana y cuya parte más conocida refiere la perspectiva india de la conquista. Como convincentemente argumenta Georges Baudot, por su densidad semántica y la fecha de su redacción, este texto fue muy probablemente escrito por un tlacuilo náhuatl, quien aprovechó el modelo alfabético y vació allí una poderosa narrativa. (Baudot, 2004: 262-263) La puesta al día con el nuevo orden colonial que muestra este tlacuilo sugiere un repertorio ampliamente practicado en los siglos XVI y XVII. Las estrategias indígenas de resistencia en el período colonial atraviesan también al lenguaje y a los soportes de signos, asunto que en muchas ocasiones parece escapársele a Mignolo, a pesar de las declaraciones iniciales de El lado más oscuro del Renacimiento en torno al poder y la resistencia. Además, cabría agregar que los usos indígenas de la escritura alfabética pocas dé- 
cadas después de haberse redactado ese texto de los Anales históricos de la nación mexicana en muchas ocasiones se alejaban de cualquier recepción pasiva y reproducían textos sin ninguna autorización de la Iglesia. Así, en 1555, el Primer Concilio Mexicano ordena incautar todos los sermones en posesión de los indios y se mostraba temeroso de su "falseamiento" y "corrupción" e inclusive prohibía la venta a los indios de un "libro de las suertes" que circulaba en castellano. (Gruzinski, 2007: 63) Esto prueba la rápida apropiación del alfabeto latino por una multiplicidad de sujetos indios, quienes copiaban y reelaboraban los escritos que llegaban a sus manos. Por no mencionar las aceleradas transformaciones que sufre la escritura pictográfica en la segunda mitad del siglo xvi, en parte bajo el impacto del libro europeo de viñetas, analizado por Gruzinski, todo lo cual prueba que las habilidades gráficas condensadas en las pictografías lejos de ser un arcaísmo, estaban audazmente abiertas a nuevas modalidades y a reformulaciones inéditas. Por último, en el plano de los usos estratégicos indígenas del alfabeto latino, cabría recordar que durante la segunda mitad del siglo XVI escritores indígenas e intérpretes-los nahuatlatos- redactaron solicitudes, testamentos, actas de venta y de donación. Enviaban querellas y denuncias a los jueces eclesiásticos, al virrey, al corregidor o a un visitador. Para 1545 se procuran el texto de las leyes que los favorecen, lo cual nuevamente muestra la existencia de una actitud de apertura estratégica al nuevo orden colonial. A grandes rasgos, podríamos afirmar que si bien de parte de los misioneros hubo cierta celebración renacentista de la letra y la escritura, que documenta Mignolo en El lado más oscuro del Renacimiento, esa constatación no es suficiente para dar cuenta de la complejidad de las interacciones entre el alfabeto latino y las formas pictográficas durante los siglos XVI y XVII.

\section{EN TORNO AL “HABLA” DE CALIBÁN}

La temática del habla de Calibán, el personaje de La tempestad de Shakespeare, nos podría guiar también en este terreno de la reflexión acerca del "discurso colonial". Particularmente, si consideramos que en las múltiples lecturas que esta figura ha suscitado en el pensamiento latinoamericano y caribeño, ha cobrado cada vez más relevancia su condición de sujeto esclavizado e invadido por Próspero. En el marco de una serie de ensayos que abren diálogo con las perspectivas poscoloniales, el crítico literario 
Julio Ortega ha vuelto sobre el problema del habla de Calibán (Ortega, 2010: 55-81). Pero convendría, quizá, recordar primero la forma en la que el filósofo argentino Arturo Andrés Roig, en su clásico libro Teoría y crítica del pensamiento latinoamericano, presenta a Calibán como decodificador del discurso opresor:

Calibán ha llevado a cabo desde sí mismo una transmutación axiológica, ha puesto a su servicio un bien, cambiándole de signo valorativo. El habla de dominación se transforma en su boca de ahora en adelante, en un habla de liberación. Mas, este hecho no podría haber tenido lugar si no hubiera habido un cambio dentro del sistema de relaciones humanas, el que consiste de modo muy simple en que Calibán, de ser un medio de carácter instrumental, se ha reconocido a sí mismo como fin, aun cuando el antiguo amo se niegue a efectuar por su parte ese reconocimiento, en cuanto reconocimiento del otro. Ya llegará a producirse algún día ese segundo reconocimiento, mas no será fruto del nuevo uso dado a la lengua por parte del esclavo, aun cuando este hecho sea de singular importancia y en ocasiones decisivo, sino cuando el amo, acorralado por la violencia que él mismo ha generado, descubra que los discursos que le preparaba Ariel, como colaborador intelectual, ya no tienen la eficacia que mostraban en un comienzo y que todo el mundo de justificaciones 'espirituales' se ha derrumbado posiblemente junto con su propio poder de dominación. Un nuevo hombre ha surgido que, por la fuerza de los hechos, no renuncia al 'legado' impuesto, en este caso la lengua o los instrumentos de trabajo, sino que da a ellos un nuevo valor, su valor intrínseco y crea una 'lengua para maldecir', lo cual supone una forma espontánea de decodificación del discurso opresor, como crea un nuevo uso de la hoz o del machete que ya no 'siegan doradas mieses', ni 'cortan dulces cañas', labores cantadas idílicamente por tantos arieles en el mundo (Roig, 1981: 51-52).

Este agudo análisis de Roig, basado en la forma en que Calibán decodifica el discurso que lo mantiene sometido, contiene varios elementos que es necesario desglosar. Aquí entra en juego Ariel, personaje sutil y espiritual que está al servicio de Próspero en La tempestad. Para lo que nos ocupa basta indicar que, en Calibán, ensayo de Roberto Fernández Retamar que comienza este debate sobre nuevas bases, Ariel simboliza a los intelectuales. (Fernández Retamar, 2004) Tendríamos, entonces, no solamente la relación de poder y de dominio colonial entre Próspero y Calibán; también es preciso incluir las justificaciones discursivas e ideológicas de esta situación elaboradas por Ariel. En su ensayo de 1971, Fer- 
nández Retamar hace un llamado a los intelectuales, a los arieles, a tomar partido por Calibán.

En la lectura de Julio Ortega, hay otros elementos a considerar para iluminar la problemática del "discurso colonial" y, en este caso, la cuestión del habla de Calibán. Por ejemplo, Ortega se detiene a examinar la misma escena que Roig, en la que Calibán injuria a Próspero:

El lenguaje, en efecto, le ha dado la subjetividad contradictoria. Pero no sólo porque el lenguaje lo haya enseñado a maldecir sino porque maldecir es la ganancia que él reconoce de haber aprendido a hablar. Es 'mi ganancia', dice, porque ésa es la parte sólo suya, la prueba de su libertad interior en el saber y el reconocer. Maldecir es la metáfora de un habla propia, de una apropiación consciente, sarcástica y rebajadora. Por eso, de inmediato habla en un aparte, reconociendo el poder de su amo y la necesidad de controlar la escena de habla: 'I must obey', se dice a sí mismo, temeroso del poder del mago. El lenguaje aprendido le permite conocer sus límites, afirmar su cuerpo, representar su papel. Pero también le permite actuar la identidad de nativo que le atribuyen los otros, incluso jugar con su nombre y su reputación de malvado. (Ortega, 2010: 61)

Este tipo de reflexiones pretenden situarse ante un complejo proceso, aquel relativo al aprendizaje de la lengua colonial por parte de los sujetos dominados e invadidos. Ortega enfatiza aquí, y desarrollará con algo de detalle, la cuestión de los espacios culturales mixtos e intermedios que surgen como resultado de estos acontecimientos históricos. De hecho, una vertiente de los estudios poscoloniales, desde sus inicios en el marco de la obra de Homi Bhabha, ha buscado poner de relieve los espacios culturales que suponen una pertenencia simultánea a dos horizontes, el dominante y hegemónico, por un lado, y, paralelamente, el invadido y colonizado. Se trata de un enfoque que, efectivamente, puede iluminar algunas dimensiones del periodo colonial, estrictamente, así como de sus secuelas que se prolongan en la época "poscolonial". Ello, con algunas precauciones históricas y metodológicas, ya que estos “espacios mixtos” sólo expresan un repertorio, entre varios, del conjunto de relaciones sociales que se edificaron tras el impacto colonial. Si bien como modelo de análisis puede resultar sugerente, convendría acotar sus alcances y, en muchos casos, enfatizar la asimetría que la condición colonial impuso a los sujetos dominados. En el terreno del discurso y la semiosis que nos ocupa ahora y, particularmente, en el marco del habla de Calibán que interpreta Julio Ortega, este aprendizaje de la lengua colonial le parecerá un atisbo de la 
situación histórica enfrentada por los sujetos "mestizos" del siglo xvir. Comentando la escena en la que Calibán indica que fue despojado de su isla, para posteriormente aprender la lengua de Próspero, Ortega señala:

Esta declaración señala la relación amo/esclavo como central a la forma del poder colonial. Señala también algo menos obvio y más importante: el desgarramiento del nativo, colonizado por el lenguaje, y hasta por la fe adquirida (ha aprendido, nos dice, a nombrar las estrellas, referencia a Génesis 1.16); pero ese aprendizaje es a costa de su heredad y pertenencia. Su identidad es, ahora, ese despojo. Este gesto tiene una poderosa resonancia en la América del siglo xvir y alude al discurso de los mestizos, esos primeros habitantes de la hibridez colonial. Como Calibán, los mestizos desafían a la autoridad colonial al declarar que la tierra es suya por doble filiación: la heredaron de sus madres y la ganaron por sus padres. Propiedad y conquista, herencia y ganancia se suman en ellos, que son hijos de la violencia fundadora pero también padres del nuevo discurso americano, el que suma las discordias del origen y las opciones del porvenir. (Ortega, 2010: 63)

Este problema de los espacios culturales mixtos y, particularmente, de las condiciones de enunciación de los sujetos mestizos en el siglo XVII se podría complejizar y ampliar si volteáramos la mirada hacia el perfil de las "repúblicas de indios" que desde 1570 la administración virreinal va estableciendo. Tras la catástrofe demográfica indígena acaecida en buena parte del siglo XVI (y que se prolongaría hasta el siglo XVII), la concentración territorial de las comunidades supervivientes, ordenada por las autoridades coloniales, dará origen a un proceso cultural de larga duración. Así, estos pueblos de indios expresarán quizá con mayor nitidez la pertenencia a un espacio mixto, ya que los indios que se trasladaron a las ciudades se aculturaban de manera más notoria, generando a la par el fenómeno histórico y social de un mestizaje con dominancia hispánica. Mientras que las 'repúblicas de indios' "fueron crisoles en que se fundieron e integraron elementos culturales nativos y europeos que, como resultado de un lento proceso de aculturación, originarían culturas coloniales mixtas de vida muy larga." (Céspedes, 1976: 128) En estos pueblos se ejercía la autoridad colonial por medio de un 'corregidor de indios', ayudado por empleados subalternos e intérpretes, y se podría argumentar que configuraron un 'espacio intermedio' o mixto en el que las prácticas y las lenguas indias encontraron condiciones para su persistencia, a pesar de la cristianización y del control político, así como de la continuidad del tributo. Se trata de un espacio histórico y social que, como sugeríamos, supone la existencia 
de un repertorio diferenciado ante la dominación colonial. Esto nos lleva a pensar que, para clarificar estos temas, nunca es suficiente la precaución epistemológica frente al fenómeno colonial, ya que este proceso histórico de ninguna manera es monolítico; tiene múltiples facetas, y sus variadas dimensiones no se captan recurriendo a esquemas o a moldes conceptuales uniformes.

\section{TEORÍA POSCOLONIAL Y DISCURSO COLONIAL: OTRAS COORDENADAS}

Tras el recorrido que hemos realizado, convendría, tentativamente, regresar a los planteamientos acerca del "discurso colonial" que se han expresado con fuerza en el marco de la "teoría poscolonial". Me refiero aquí a los análisis y enfoques en torno al colonialismo que no han sido pensados exclusivamente a partir de la historia colonial en América Latina, y que han utilizado diversas coordenadas espacio-temporales para elaborar sus construcciones conceptuales. De esta forma, al ampliar la mirada e incluir, aunque sea brevemente, esas propuestas teóricas, podrá vislumbrarse un conjunto de cuestiones que estaremos en condiciones de comparar y referir al ámbito del "discurso colonial" en nuestra América, asunto que hemos ya esbozado.

Ania Loomba, al introducir la cuestión de la 'ideología' en el marco de su análisis del tránsito teórico del "colonialismo" al "discurso colonial", remite a una problemática a la que ya hemos aludido. Loomba sitúa, entre otros, al pensamiento de Gramsci y Althusser en el panorama teórico contemporáneo y busca mostrar su pertinencia para la consideración de la dominación colonial. (Loomba, 2005: 30-35) En el caso de Gramsci, al examinar esta autora la noción de hegemonía, y particularmente la manera en que ha sido utilizada esa categoría para dar cuenta de algunos procesos coloniales, el énfasis recae en el papel que la subjetividad y la ideología cumplen en los procesos de dominación. Aquí nuevamente nos enfrentamos a un conjunto de problemáticas que ya habían sido implícitamente referidas en los abordajes del "discurso colonial" en América Latina. Al aseverar que los regímenes coloniales buscaron obtener el consenso de algunos grupos "nativos", mientras excluían a otros colectivos del espacio de la sociedad civil, Loomba se está cuestionando acerca del papel del "consenso" de los dominados en esos contextos. Particularmente, se 
enfatiza la transformación de las ideas y las prácticas de los dominados, de tal forma que el poder colonial no se instaura solamente "desde arriba".

Por otro lado, en su revisión de la teoría althusseriana de la ideología, y del impacto que tuvo en otras propuestas teóricas, Loomba enfatiza la dimensión 'material' de los aparatos ideológicos. De hecho, aquí podríamos situar un ámbito problemático que ya hemos alcanzado a observar en algunos de los autores que hemos revisado:

El problema es importante para la teoría poscolonial, la cual, como veremos, ha sido acusada de ser incapaz de mantener cualquier distinción entre cuestiones de representación, lenguaje y cultura, por un lado, y realidades materiales y económicas por el otro. Éste es un asunto delicado, ya que si bien hay una obvia necesidad de interrelacionar ambos [...] también se requiere mantener cierta distinción, para que la especificidad de cada uno de los niveles no se desdibuje. (Loomba, 2005: 34)

Este planteamiento, en este caso elaborado pensando en la teoría poscolonial que ha tenido como figuras más representativas a Edward Said, Gayatri Spivak o Homi Bhabha, sugiere algunas tensiones conceptuales que podremos ver también con cierta nitidez en los marcos analíticos de la producción poscolonial/decolonial latinoamericana. En primer lugar, cabría acotar que se trata de una cuestión que no es resuelta de manera uniforme en los estudios y textos que hemos revisado. Aunque también se podría afirmar que se trata de un ámbito que parece haberse desplazado como problemática específica: la interrelación entre los procesos de dominación/explotación propios del poder colonial, y las formaciones discursivas que atraviesan a esas sociedades no se perfila como un asunto que planteara cuestiones a resolver. Más bien, en muchos estudios, se parte del ámbito de la representación, el discurso y la semiosis, como hemos podido ilustrar a lo largo de este trabajo, lo cual abre ciertas interrogantes.

Quizá sólo sea necesario agregar que si nos detuviéramos para considerar uno de los ejes fundamentales que atraviesa a los estudios sobre discurso colonial en América veríamos que, a partir de un conjunto delimitado de enunciados, se transita a la caracterización de la "lógica colonial". Encontramos, por una parte, el esfuerzo por mostrar el tipo de representaciones textuales sobre el "Otro" sujeto de la dominación que pone en movimiento la maquinaria colonialista. Aquí, lo que se pone sobre la mesa básicamente son las connotaciones, cultural e históricamente señalables, que acompañan al control colonial de los sujetos. Así, hay una serie 
o cadena de asociaciones en la representación textual del caribe mostrada por Jaúregui. El caribe se identificará o hará equivaler con la ferocidad, la ausencia de leyes, etc. En este plano, lo que se muestra es que la práctica de la dominación colonial supone la generación de unos estereotipos, de unas representaciones textuales o icónicas sobre el "Otro" cargadas axiológicamente. Y, en principio, es necesario reconocer la dificultad de desglosar analíticamente y separar tajantemente las prácticas de dominación del universo enunciativo y de las formaciones discursivas que, en buena medida, les son constitutivas. En esta tensión entre lo discursivo y lo extradiscursivo se abre justamente el terreno problemático en el que se sitúan algunas de las propuestas teóricas que hemos revisado. Esto no obsta para que se reconozca, en primer lugar, las múltiples dimensiones que pueden adquirir estos procesos, en algunos casos ambiguos y polivalentes, como bien lo muestra el ejemplo de Calibán, en su resistencia/apropiación del discurso dominante. Y, por último, es necesario hacer un llamado a no obliterar o desplazar los mecanismos materiales de la dominación que estos procesos discursivos en muchas ocasiones testifican. En el afán por rendirle tributo al "fragmento", se puede perder la capacidad de plantearnos un enfoque complejo en torno a la dominación colonial en nuestra América, control ejercido en diversos y complementarios niveles: en el terreno de la explotación del trabajo, en el ámbito simbólico/religioso, y ciertamente en la esfera textual, discursiva y semiótica.

BIBLIOGRAFÍA

ACHÚGAR, H., (1998) "Leones, cazadores e historiadores. A propósito de las políticas de la memoria y del conocimiento" en Santiago Castro-Gómez/ Eduardo Mendieta (ed.), Teorías sin disciplina. Latinoamericanismo, poscolonialidad y globalización en debate, México: Miguel Ángel Porrúa, pp. 108-120

BAUDOT, G., (2004); Pervivencia del mundo azteca en el México virreinal, México: UNAM

CÉSPEDES, G., (1976), América Latina colonial hasta 1650, México: SEP

FERNÁNDEZ RETAMAR, R. (2004); Todo Calibán, Buenos Aires: CLACSO

GRUZINSKI, S., (2007); La colonización de lo imaginario. Sociedades indígenas y occidentalización en el México español. Siglos XVI-XVIII, México: Fondo de Cultura Económica 
JÁUREGUI, C., (2008); Canibalia. Canibalismo, calibanismo, antropofagia cultural y consumo en América Latina, Madrid/Frankfurt Am Main: Iberoamericana/Vervuert

LOOMBA, A., (2005); Colonialism/Postcolonialism, Nueva York: Routledge

MIGNOLO, W., (1995); The darker side of the Renaissance. Literacy, territoriality and colonization, Ann Arbor: The University of Michigan Press

ORTEGA, J., (2010); El sujeto dialógico. Negociaciones de la modernidad conflictiva, México: ITESM/Fondo de Cultura Económica

ROIG, A.A., (1981); Teoría y crítica del pensamiento latinoamericano, México: Fondo de Cultura Económica

ROIG, A.A., (2001); Caminos de la filosofía latinoamericana, Maracaibo: Universidad del Zulia

SAID, E., (2002); Orientalismo, Barcelona: Random House Mondadori

SEED, P., (1991); "Colonial and Postcolonial Discourse", en Latin American Research Review, 6, 3, pp. 181-200

VEGA, M.J., (2003); Imperios de papel. Introducción a la crítica poscolonial, Barcelona: Crítica

VIDAL, H., (1993); "The Concept of Colonial and Postcolonial Discourse: A Perspective from Literary Criticism", en Latin American Research Review, 28, 3, pp. 113-119 